\title{
EDITORIAL
}

\section{Preventing sepsis in healthcare - 200 years after the birth of Ignaz Semmelweis}

Didier Pittet ${ }^{1}$, Benedetta Allegranzi ${ }^{2}$

1. Infection Control Programme and World Health Organization Collaborating Centre on Patient Safety, University of Geneva Hospitals and Faculty of Medicine, Geneva, Switzerland

2. Infection Prevention and Control Global Unit, Department of Service Delivery and Safety, World Health Organization (WHO), Geneva, Switzerland

Correspondence: Didier Pittet (Didier.Pittet@hcuge.ch)

Citation style for this article:

Pittet Didier, Allegranzi Benedetta. Preventing sepsis in healthcare - 200 years after the birth of Ignaz Semmelweis. Euro Surveill. 2018;23(18):pii=18-00222. https://doi.org/10.2807/1560-7917.ES.2018.23.18.18-00222

Article submitted on 27 Apr 2018 / accepted on 03 May 2018 / published on 03 May 2018

The year 2018 marks the 20oth anniversary of the birth of Ignaz Philipp Semmelweis, the 'father' and pioneer of improved infection prevention and control (IPC) practices. Born on 1 July 1818 in Buda, Hungary, Semmelweis was the son of a respected merchant. His family home was close to Buda Castle where he went to school. Semmelweis initially pursued an arts degree at the university in Pest, a separate town from Buda at the time $[1,2]$, and then moved on to medical studies from 1837, first in Pest, then in Vienna, Austria. In 1846, Semmelweis worked as an assistant in obstetrics at the Vienna General Hospital, one of the largest obstetric clinics in Europe. Apart from working with patients, he was in charge of the supervision of students and medical autopsies.

In the mid-19th century, childbed fever, also called puerperal fever, was a common disease affecting women throughout Europe. The frequently lethal condition was less often acquired by women giving birth at home compared with those delivering in healthcare institutions [3]. The disease was widely attributed to miasma, 'an emanation or an atmosphere that hovers in the surroundings and causes sickness to those exposed to it by the pervasiveness of its malignant presence'. The high mortality rate among pregnant women, mostly related to infectious diseases and sepsis, was considered to be associated with local cosmotelluric forces, hygrometric forces, polar currents, or radiation from the constellations [1-3].

At the Vienna General Hospital, pregnant women were admitted to one of two obstetric wards on alternate days. The only difference between the two wards was that one was staffed exclusively by midwives, while in the other ward medical students and doctors were in charge of deliveries and conducted autopsies on dead women in the nearby room. However, mortality from childbed fever was much higher in the latter ward. As soon as he started working in this ward, Semmelweis was struck by the difference $[2,4]$. The clue to the solution of this enigma was provided by the death of Semmelweis' friend and colleague, Jakob Kolletschka, who developed a condition resembling childbed fever following a scalpel laceration while supervising an autopsy. This led Semmelweis to hypothesise that the elevated mortality rate in the ward was due to the contamination of the hands of medical students and doctors with 'cadaverous particles' during autopsies $[1,2,4]$.

On 15 May 1847, Semmelweis instituted his groundbreaking intervention and ordered everyone to scrub their hands with a chlorinated lime solution when moving from the autopsy room to the delivery room [4]. The impact was immediate and dramatic and soon the mortality rate became comparable between the two wards $[1,2,4]$. The 'Semmelweis recipe' included one part chlorinated lime and 24 parts water, ultimately proven to be extremely effective in annihilating any bacteria [5], much more than soap, and at least comparable with the most effective alcohol-based hand rubs recommended today as the gold standard for patient care [6]. The chlorinated lime solution was chosen by Semmelweis after he had met with the housekeeping staff and looked for the strongest product in use at the hospital: 'it smells, it itches eyes, it's strong on your hands ...it must work!'.

In early 1848, however, a woman with cancer of the uterus with a purulent discharge was examined, and 11 of 12 women examined consecutively in the ward hereafter developed childbirth fever over the next few days $[1,2,4]$. Semmelweis' concluded that the disease could be spread from necrotic discharges from living patients as well as autopsy material. From that date onwards, he recommended hand scrubbing also between contacts with each and every patient. These instructions are basis for the present World Health Organization 


\section{FIGURE 1}

Die Aetiologie, der Begriff und die Prophylaxis des

Kindbettfiebers (The aetiology, concept and prophylaxis of childbed fever) by Ignaz Philipp Semmelweis, 1861

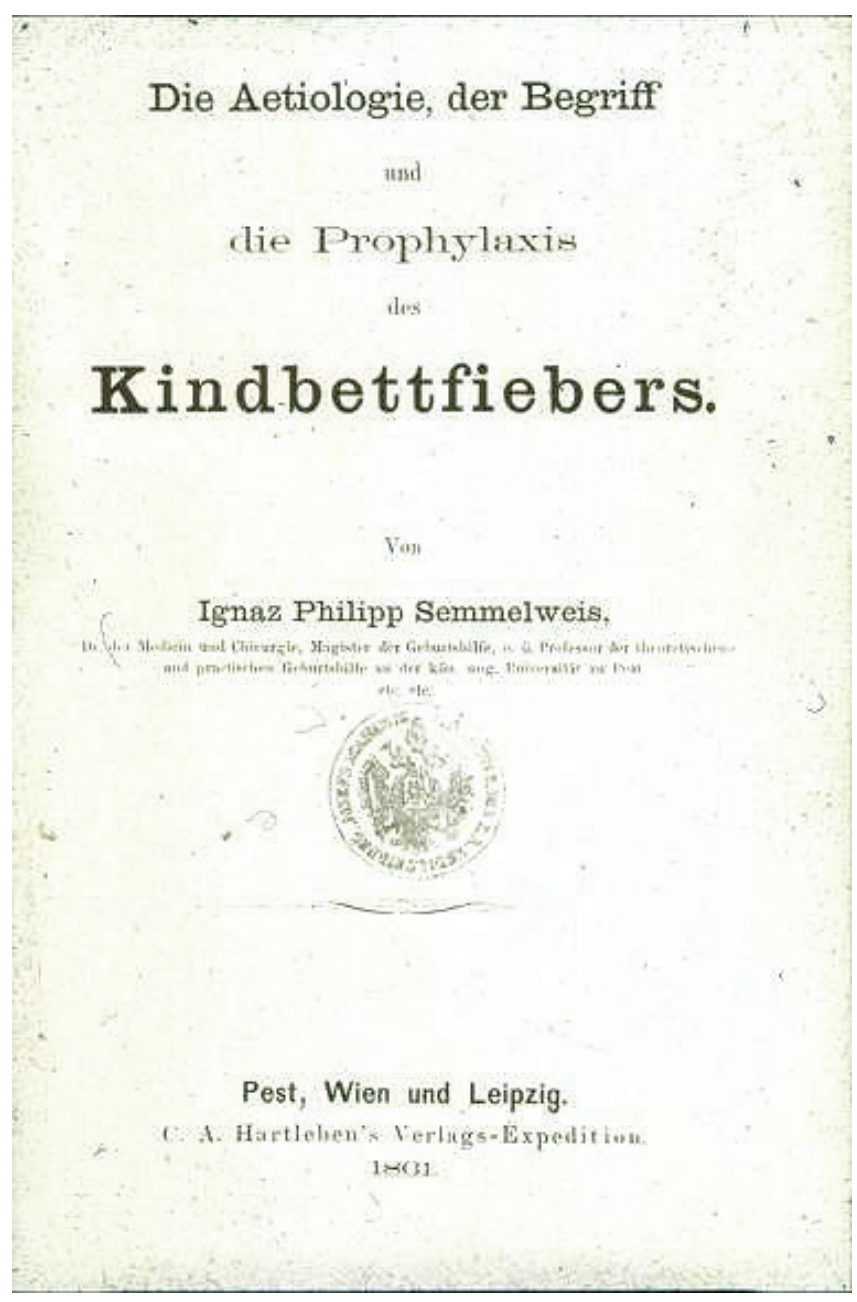

Photo: D. Pittet, reproduced with permission.

(WHO) concepts behind recommendations on 'When to hand rub', and 'My 5 moments for hand hygiene' $[6,7]$.

Semmelweis' interventions proved effective in reducing maternal mortality, but they were unpopular among students and colleagues and his contract was not renewed in March 1849 [1,2]. He returned to Budapest, made the same observations, conducted the same intervention with the same impact on patient outcomes, and lost his job once again. In 1861, Semmelweis finally published his seminal work on the aetiology of childbed fever (Figure 1). Sadly, he was committed to a mental asylum in 1865 where he died shortly after admission. The French author and physician, Louis-Ferdinand Céline ended his doctoral dissertation that was dedicated to Semmelweis' work [8] with the sentence: '... it would seem that his discovery exceeded the forces of his genius. It was, perhaps, the root cause of all his misfortunes'.

\section{FIGURE 2}

'How to prevent sepsis in health care'

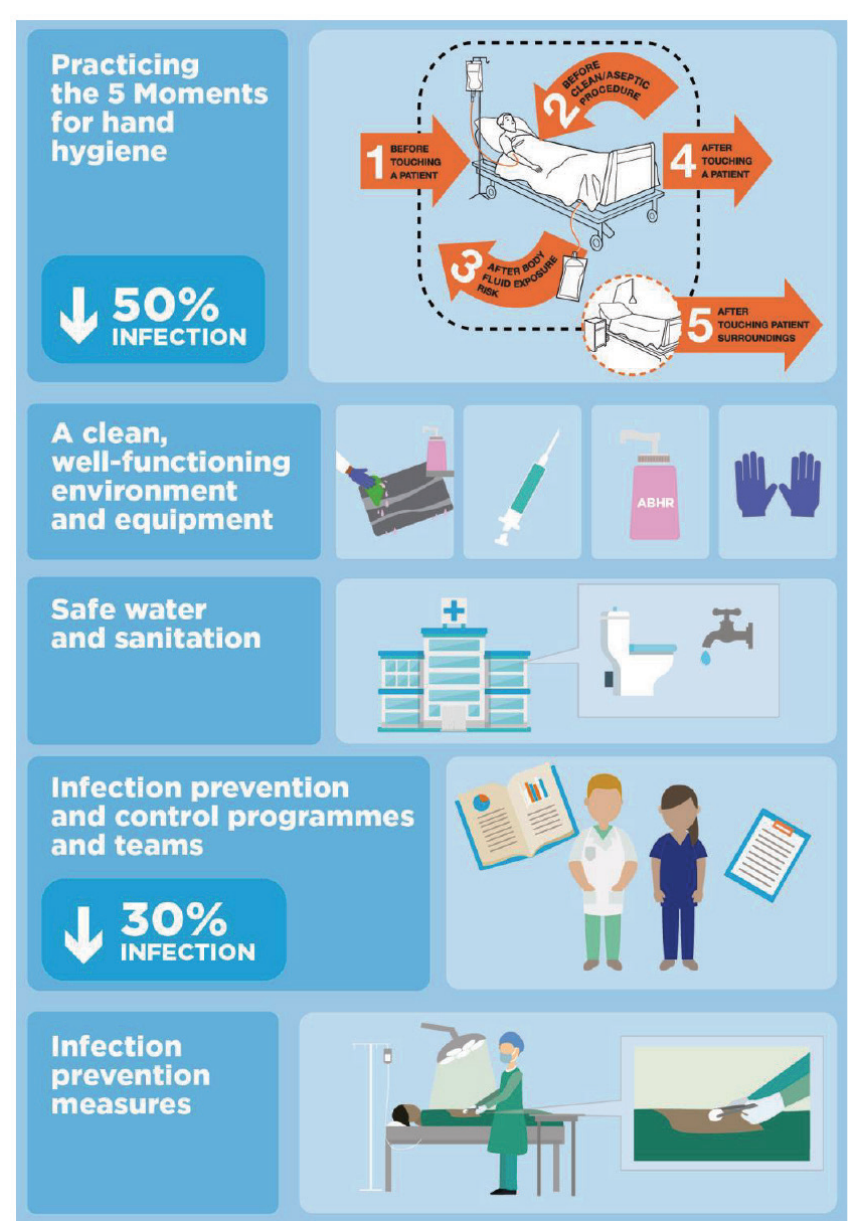

Extract from a 2018 World Health Organization Infographic.

Indeed, Semmelweis was a pioneer in scientific risk assessment and in identifying the source of transmission, including conducting an effective intervention. His intervention can be considered as a cluster-randomised controlled trial with random allocation (admission on alternate days) and appropriate long-term follow-up until discharge from the hospital [1-4]. Today, puerperal fever would be classified as maternal sepsis. Sepsis is a life-threatening organ dysfunction caused by a dysregulated host response to infection caused by any type of pathogen that can be acquired either in the community or in healthcare settings [9]. If not recognised early and managed promptly, sepsis can lead to septic shock, multiple organ failure and death. Sepsis remains a public health problem of global concern: more than 30 million people worldwide are estimated to suffer from sepsis each year [10]. One in 10 deaths associated with pregnancy and childbirth is due to sepsis, with more than $95 \%$ of deaths due to maternal sepsis occurring in low- and middle-income countries [11]. One million newborn deaths are associated with maternal infection, such as sepsis, each year [12]. Remarkable progress has been made in reducing deaths due to maternal sepsis with global estimates decreasing by 


\section{FIGURE 3}

'It's in your hands; prevent sepsis in health care'

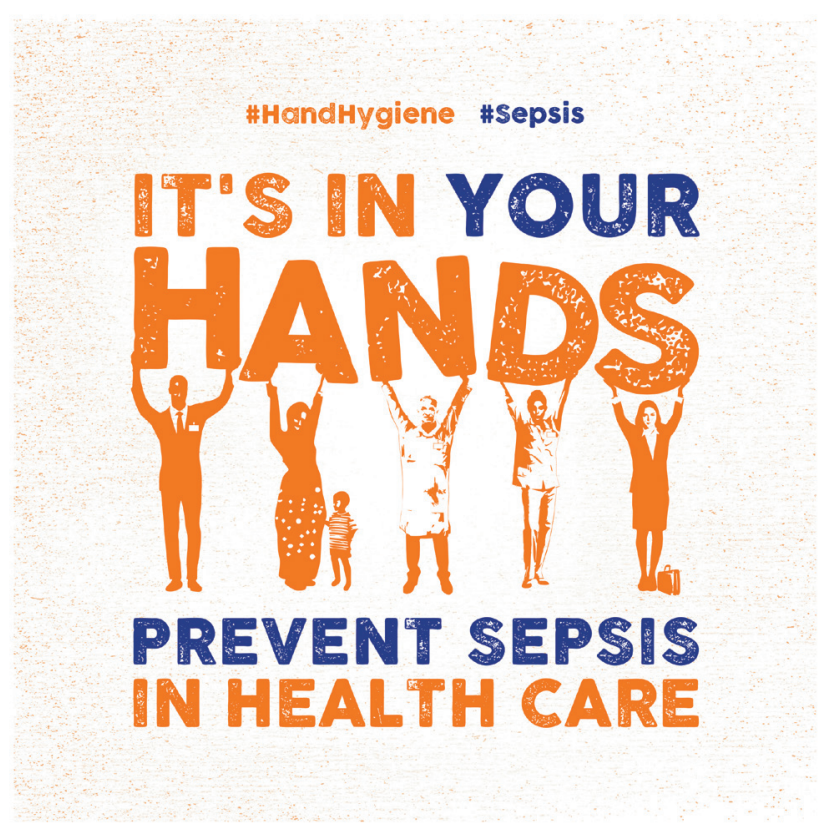

5 May 2018 WHO 'SAVE LIVES: Clean Your Hands' campaign slogan and main promotional image. 2018 hashtags are: \#HandHygiene \#Sepsis. Campaign participants are invited to submit photos/ selfies holding a board with the slogan and hashtags at www. CleanHandsSaveLives.org.

$27.7 \%$ between 2005 and 2015 , but death due to neonatal sepsis is one of only a few remaining exceptions where the reduction has been limited [13]. Although pooled estimates are not available in Europe, mortality reduction from hospital-treated sepsis among children was for example, observed in Germany between 2007 and 2013 (from 124.8 to 104.8 per 100,000 population) [14].

Antimicrobial resistance is a major factor determining clinical unresponsiveness to treatment and a rapid evolution to sepsis and septic shock. Sepsis patients with resistant pathogens have been found to have a higher risk of mortality. For example, less than 50\% of children under 5 years of age with acute respiratory infection, diarrhoea or fever receive appropriate care in Africa [15], thus posing them at risk of severe complications, including sepsis. In Europe, carbapenem resistance has been increasing in the last years, in particular among pathogens such as Klebsiella pneumoniae, Pseudomonas aeruginosa and Acinetobacter spp. that often cause healthcare-associated infections [16]; patients infected by carbapenem-resistant pathogens have significantly higher mortality than those affected by carbapenem-susceptible isolates $[17,18]$.

Sepsis is avoidable in both the community and healthcare settings by preventing infection and its evolution into more severe conditions (Figure 2) [19]. The former is mainly achieved through vaccination, implementation of basic IPC good practices, and improvements in sanitation, nutrition and the delivery of clean water. There is strong evidence to support the positive impact of access to healthcare services, rapid diagnosis, and prompt and appropriate clinical management on infectious disease outcomes. Establishing IPC programmes and teams in hospitals can reduce healthcare-associated infections by at least 30\% [20] and, based on Semmelweis' lesson, hand hygiene alone can reduce them by half [21]. Similarly, handwashing improvements can lead to a $48 \%$ reduction of diarrhoeal diseases in the community [22].

Hand hygiene is the cornerstone of good IPC practices, both in high- and low-resource settings, and it is actively promoted every year on and around 5 May by the WHO 'SAVE LIVES: Clean Your Hands' campaign. Over the last decade, more than 20,000 health facilities from over 179 countries have registered for the campaign and many more participate regularly. The focus in 2018 is on the prevention of sepsis with the slogan 'It's in your hands - prevent sepsis in health care' (Figure 3).

The calls to action are universal (Table). They invite to join hands and make sure that the commitment to overcoming sepsis is as strong as the exemplary and unmatched commitment of Semmelweis. In this way, each and every one has the possibility to contribute to the implementation of the 2017 World Health Assembly resolution focused on 'Improving the prevention, diagnosis and clinical management of sepsis' [23] and to achieving the United Nations Sustainable Development Goals, which target maternal, neonatal and under-5 child mortality.

To mark the 2ooth anniversary of Ignaz Semmelweis' birth, Eurosurveillance highlights work on healthcareassociated infections and IPC in a special collection 'Hospital infection control - 200 years after the birth of Ignaz Semmelweis'. 
5 May 2018 WHO 'SAVE LIVES: Clean Your Hands' campaign calls to action

\begin{tabular}{|l|l|}
\hline Target group & Call to action \\
\hline Health workers & 'Take 5 moments ${ }^{\text {a }}$ to clean your hands to prevent sepsis in healthcare' \\
\hline IPC leaders & 'Be a champion in promoting hand hygiene to prevent sepsis in healthcare’ \\
\hline Health facility leaders & 'Prevent sepsis in healthcare, make hand hygiene a quality indicator in your hospital’ \\
\hline Ministries of health & $\begin{array}{l}\text { 'Implement the } 2017 \text { WHA sepsis resolution. Make hand hygiene a national marker of healthcare } \\
\text { quality' }\end{array}$ \\
\hline Patient advocacy groups & 'Ask for 5 moments of clean hands to prevent sepsis in healthcare’ \\
\hline
\end{tabular}

IPC: infection prevention and control; WHA: World Health Assembly; WHO: World Health Organization.

a Refers to the 'My 5 moments for hand hygiene' as published in the WHO Guidelines on hand hygiene in healthcare [6,7].

\section{Acknowledgements}

The campaign is supported by the World Health Organization (WHO), Geneva, Switzerland, and the Infection Control Programme and WHO Collaborating Centre on Patient Safety (SPCI/WCC), University of Geneva Hospitals and Faculty of Medicine, Geneva, Switzerland; hand hygiene research activities at the SPCI/WCC are also supported by the Swiss National Science Foundation (grant no.32003B_163262).

The authors alone are responsible for the views expressed in this article and they do not necessarily represent the views, decisions or policies of the institutions with which they are affiliated. WHO takes no responsibility for the information provided or the views expressed in this editorial.

\section{Conflict of interest}

None declared.

\section{Authors' contributions}

Both authors contributed to the draft of the editorial.

\section{References}

1. Pittet D, Boyce J. Hand hygiene during patient care: pursuing the Semmelweis legacy. Lancet Infect Dis. 2001;1(April):9-30. https://doi.org/10.1016/S1473-3099(09)70295-6 PMID: 11871420

2. Stewardson A, Allegranzi B, Sax H, Kilpatrick C, Pittet D. Back to the future: rising to the Semmelweis challenge in hand hygiene. Future Microbiol. 2011;6(8):855-76. https://doi. org/10.2217/fmb.11.66 PMID: 21861619

3. Nuland SB. The doctor's plague: germs, childbed fever, and the strange story of Ignac Semmelweis. New York: WW Norton \& Company; 2003.

4. Semmelweis IP. Die Aetiologie, der Begriff und die Prophylaxis des Kindbezttfiebers. [Etiology, concept, and prophylaxis of childbed fever]. Pest, Vienna and Leipzig: A Hartelebens Verlags-Exhibition; 1861. German.

5. Rotter ML. Semmelweis' sesquicentennial: a littlenoted anniversary of handwashing. Curr Opin Infect Dis. 1998;11(4):457-60. https://doi.org/10.1097/00001432199808000-00011 PMID: 17033411

6. World Health Organization (WHO). WHO Guidelines on hand hygiene in health care. Geneva: WHO; 2009. Available from: http://www.who.int/gpsc/5may/tools/9789241597906/en/

7. Sax H, Allegranzi B, Uçkay I, Larson E, Boyce J, Pittet D. 'My five moments for hand hygiene': a user-centred design approach to understand, train, monitor and report hand hygiene. J Hosp Infect. 2007;67(1):9-21. https://doi. org/10.1016/j.jhin.2007.06.004 PMID: 17719685

8. Céline LF. Semmelweis. Paris, France: Ed. Gallimard (Collection “L'Imaginaire”); 1999.
9. Singer M, Deutschman CS, Seymour CW, Shankar-Hari M, Annane D, Bauer M, et al. The Third International Consensus Definitions for Sepsis and Septic Shock (Sepsis-3). JAMA. 2016;315(8):801-10. https://doi.org/10.1001/jama.2016.0287 PMID: 26903338

10. Fleischmann C, Scherag A, Adhikari NK, Hartog CS, Tsaganos T, Schlattmann P, et al. Assessment of global incidence and mortality of hospital-treated sepsis. Current estimates and limitations. Am J Respir Crit Care Med. 2016;193(3):259-72. https://doi.org/10.1164/rccm.201504-07810C PMID: 26414292

11. Say L, Chou D, Gemmill A, Tunçalp Ö, Moller AB, Daniels J, et al. Global causes of maternal death: a WHO systematic analysis. Lancet Glob Health. 2014;2(6):e323-33. https://doi. org/10.1016/S2214-109X(14)70227-X PMID: 25103301

12. Black RE, Laxminarayan R, Temmerman M, Walker N, editors. Reproductive, maternal, newborn, and child health: disease control priorities. Third ed. (vol. 2). Washington, DC: The International Bank for Reconstruction and Development/The World Bank; 2016.

13. Wang H, Naghavi M, Allen C, Barber RM, Bhutta ZA, Carter $A$, et al. Global, regional, and national life expectancy, allcause mortality, and cause-specific mortality for 249 causes of death, 1980-2015: a systematic analysis for the Global Burden of Disease Study 2015. Lancet. 2016;388(10053):1459544. https://doi.org/10.1016/S0140-6736(16)31012-1 PMID: 27733281

14. Fleischmann-Struzek C, Goldfarb DM, Schlattmann P, Schlapbach LJ, Reinhart K, Kissoon N. The global burden of paediatric and neonatal sepsis: a systematic review. Lancet Respir Med. 2018;6(3):223-30. https://doi.org/10.1016/S22132600(18)30063-8 PMID: 29508706

15. Agyepong IA, Sewankambo N, Binagwaho A, Coll-Seck AM, Corrah T, Ezeh A, et al. The path to longer and healthier lives for all Africans by 2030: the Lancet Commission on the future of health in sub-Saharan Africa. Lancet. 2018;390(10114):280359. https://doi.org/10.1016/S0140-6736(17)31509-X PMID: 28917958

16. European Centre for Disease Prevention and Control (ECDC). Surveillance of antimicrobial resistance in Europe 2016. Annual Report of the European Antimicrobial Resistance Surveillance Network (EARS-Net). Stockholm: ECDC; 2017. Available from: https://www.ecdc.europa.eu/sites/portal/files/documents/ AMR-surveillance-Europe-2016.pdf.

17. Zhang Y, Chen XL, Huang AW, Liu SL, Liu WJ, Zhang N, et al. Mortality attributable to carbapenem-resistant Pseudomonas aeruginosa bacteremia: a meta-analysis of cohort studies. Emerg Microbes Infect. 2016;5(3):e27. https://doi.org/10.1038/ emi.2016.22 PMID: 27004762

18. Lemos EV, de la Hoz FP, Einarson TR, McGhan WF, Quevedo $E$, Castañeda C, et al. Carbapenem resistance and mortality in patients with Acinetobacter baumannii infection: systematic review and meta-analysis. Clin Microbiol Infect. 2014;20(5):416-23. https://doi.org/10.1111/1469-0691.12363 PMID: 24131374

19. World Health Organisation (WHO). Sepsis Fact Sheet. Geneva: WHO; 2018. Available from: http://www.who.int/mediacentre/ factsheets/sepsis/en/

20. Haley RW, Culver DH, White JW, Morgan WM, Emori TG, Munn VP, et al. The efficacy of infection surveillance and control programs in preventing nosocomial infections in US hospitals. Am J Epidemiol. 1985;121(2):182-205. https://doi.org/10.1093/ oxfordjournals.aje.a113990 PMID: 4014115

21. Pittet D, Hugonnet S, Harbarth S, Mourouga P, Sauvan $\mathrm{V}$, Touveneau S, et al. Effectiveness of a hospital-wide 
programme to improve compliance with hand hygiene.

Infection Control Programme. Lancet. 2000;356(9238):1307-

12. https://doi.org/10.1016/S0140-6736(00)02814-2 PMID: 11073019

22. Cairncross S, Hunt C, Boisson S, Bostoen K, Curtis V, Fung

IC, et al. Water, sanitation and hygiene for the prevention of diarrhoea. Int J Epidemiol. 2010;39(Suppl 1):i193-205. https:// doi.org/10.1093/ije/dyq035 PMID: 20348121

23. World Health Organisation (WHO). World Health Assembly. Geneva: WHO; 2017. Available from: http://apps.who.int/gb/ ebwha/pdf files/WHA70/A70_R7-en.pdf

\section{License and copyright}

This is an open-access article distributed under the terms of the Creative Commons Attribution (CC BY 4.0) Licence. You may share and adapt the material, but must give appropriate credit to the source, provide a link to the licence, and indicate if changes were made.

This article is copyright of the authors, 2018. 